\title{
Experimental Study of Soft Rock Polymer Cement Solidification
}

\author{
Xin-Xi LIU ${ }^{1, a}$, Ping ZHANG ${ }^{1, b^{\star}}$
}

${ }^{1}$ School of Civil Engineering and Architecture, Changsha University of Science \& Technology, Changsha, Hunan 410114, China

aE-mail: liuxinxi1963@126.com

${ }^{* b}$ E-mail: 448185581@qq. com

\section{Keyword: Polymer Cement Composites, Soft Rock Slope, The effect of Curing Agent}

\begin{abstract}
The paper background is based on the soft rock slope of Yizhou--Liuzhai highway in Guangxi province. Polymer cement curing agents are used to reinforcement the soft rock slope to prevent or slow the soft rock slope softening and disintegration, improve long-term stability of soft rock slope engineering. By hydrophobic test, waterproof test, firmness experiments, the effect of coating modification experiments after polymer cement curing soft rock to study the effect of polymer cement curing agent. The results show that: through the polymer cement curing, soft rock surface wetting angle increased from $37.5^{\circ}$ to $82.9^{\circ}$, good fastness, seven days of water absorption decreased by $1.9 \%$ to $0.42 \%$, pore area per unit area of soft rock dropped from 6.54 to 3.71 .
\end{abstract}

\section{Introduction}

Many researchers for different curing study, dedicated to the development of new work curing agent and curing mechanism were studied at home and abroad. Jie Zhaohua, Zhu Bingguang polymer cement-based composite waterproof coating has been applied[3]; Gary Chang, Dong Song analyzed polymer cement-based composite waterproof coating ratio of each group on its water absorption, the tensile properties and other properties[4]; Che ping, Huang Hongwei makes polypropylene fibers, curing agents and mud compounds together into solidified fibers to Curing roadway floor Mudstone[5]; Cai Zaoyun, Kang Tianhe developed a radical solution copolymerization and sol-gel synthesis of room temperature curing silicone-modified resin, a silicone-modified resin film and soft rock surface with excellent binding properties[6]; Huang He, Shi Bing self-developed eco STW soil stabilizer so expansive soil water stability, saturated strength, anti-erosion and other physical properties of water significantly increased[7]; This thesis polymer cement composite curing agent for modified material. Static water contact angle, surface scratches law, changes in the natural water absorption tests before and after curing, American Christie company KH3000 microscopic observation of scanning electron microscopy comparative analysis of unmodified and modified mudstone hydrophobic, firmness, waterproof, microstructure analysis of change, and the exploration of strengthening mechanisms of polymer modified cementitious materials mudstone.

\section{Test Rock Samples and Modified Materials}

\section{1 Experimental Rock Samples}

The carbonaceous shale selected from soft rock to highway Guangxi six carbonaceous shale slope. It have small density of joint rock mass and big persistence, after excavation by the sun, wind, rain and other effects, can easily cause weathering, disintegration, so rock strength is reduced, causing great harm to the slope stability. Figure 1.1 shows the carbonaceous shale of X-ray diffraction patterns. Table 1.1 shows the carbonaceous shale mineral composition. 


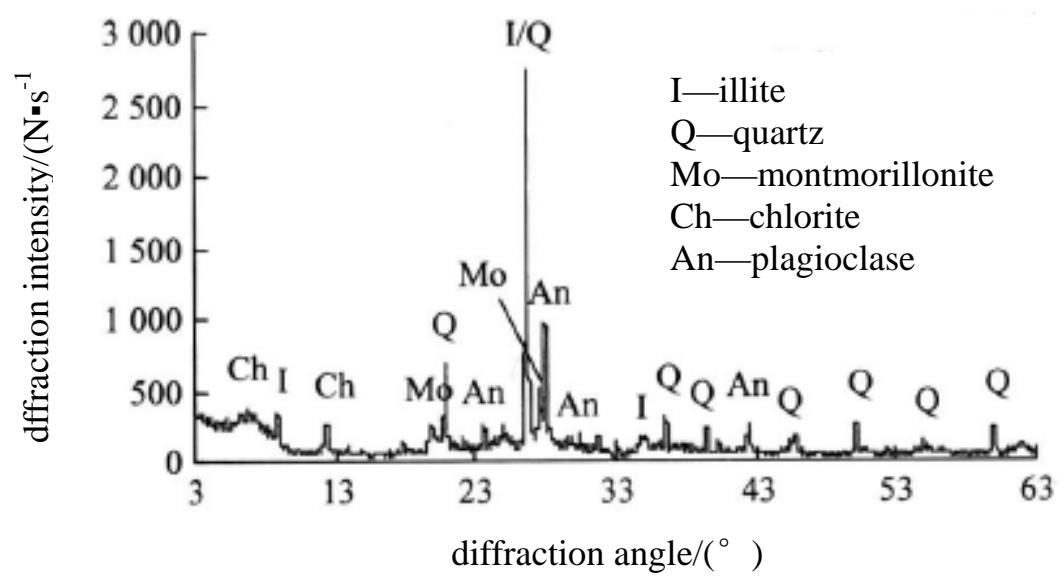

Figure 1.1 shows the carbonaceous shale of X-ray diffraction patterns.

Table 1.1 shows the carbonaceous shale mineral composition.

\begin{tabular}{|c|c|c|c|c|c|c|}
\hline Mineralogy & $\mathrm{SiO}_{2}$ & $\mathrm{Al}_{2} \mathrm{O}_{3}$ & $\mathrm{Fe}_{2} \mathrm{O}_{3}$ & $\mathrm{MgO}$ & $\mathrm{CaO}$ & $\mathrm{Na}_{2} \mathrm{O}$ \\
\hline Mineral content\% & 57.59 & 15.61 & 5.7 & 1.2 & 2.76 & 0.59 \\
\hline Mineralogy & $\mathrm{K}_{2} \mathrm{O}$ & $\mathrm{TiO}_{2}$ & $\mathrm{P}_{2} \mathrm{O}_{5}$ & $\mathrm{MnO}$ & $\mathrm{H}_{2} \mathrm{O}$ & Loss on Ignition \\
\hline Mineral content\% & 2.25 & 0.59 & 0.095 & 0.07 & 1.52 & 12.48 \\
\hline
\end{tabular}

\section{2 Modified Materials}

From the intensity of development, admixture compatibility ,stability of cement hydration heat temperature and other aspects into account, in accordance with local materials, the nearest drawn principles formulated polymer cement composite cement, Hunan Southern Cement South P. O42. 5 production of ordinary portland cement was selected. Polyacrylic acid emulsion was chosen as polymer. Polyacrylic acid emulsion solids content was 50\% cement content in the range of $30 \%$ control. Hardener mix polyacrylic acid emulsion prepared without adding defoamers, preparation of artificial mixing.

\section{Soft Rock Physical Properties Variation Before and after Modification}

\section{1 Hardener Analysis of the Hydrophobicity Test Results}

The use of soft rock samples polishing surface measure wetting angle, The fluid used for the measurement of deionized water is completed at room temperature $\left(20^{\circ} \mathrm{C}\right)$ dry air environment. As follows: (1) the digital camera on a tripod; (2) the soft rock samples on the test bed flat, adjust the height of good digital camera, making soft rock sample surface becomes a horizontal line in the digital camera lens. (3) using a syringe to drip a drop of less than $4 \mathrm{mg}$ of water droplets on the soft rock sample surface, quickly photographed with a digital camera.(4) The graphical analysis software, to measure the height $h$ and radius $r$ of the bottom photo in droplets, from equation (2.1) to calculate the wetting angle.

$$
\theta=2 \arctan (h / r)
$$

To the soft rock before curing, because the soft rock contains large amounts of strongly hydrophilic swellable clay mineral rock category, soft rock surface hydroxyl more, and at the micro-pore capillary action, soft rock will be absorbing state. Curing materials and soft rock surface hydroxyl groups interact to form an interwoven mesh structure hydrophobic polymer film, all covered in soft rock surface so soft rock surface by hydrophilic groups into a hydrophobic group, the system increases the degree of hydrophobicity surface wetting angle increased from $37.5^{\circ}$ to 82 . $9{ }^{\circ}$ after cured. 


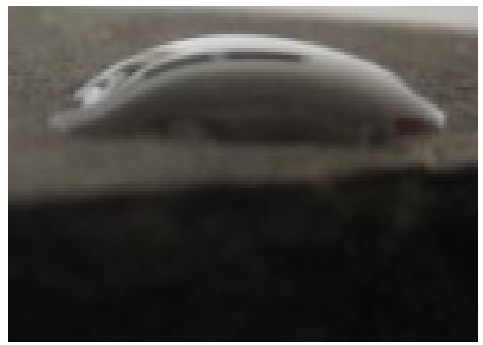

(a) Before curing

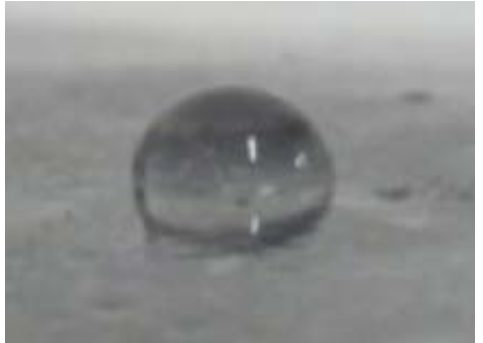

(b) cured

Figure 2. 1 droplets photos on soft rock surface

Table 2. 1 Measurements of before and after curing surface rock samples wetting angle

\begin{tabular}{|c|c|c|c|c|c|}
\hline \multicolumn{2}{|c|}{ Before curing surface wetting angle } & \multicolumn{3}{|c|}{ After curing surface wetting angle } \\
\hline $\begin{array}{c}\text { Droplet } \\
\text { diameter } \\
\mathrm{d} / \mathrm{mm}\end{array}$ & $\begin{array}{c}\text { Drops } \\
\text { height } \\
\mathrm{h} / \mathrm{mm}\end{array}$ & $\begin{array}{c}\text { Wetting } \\
\text { angle } \theta / 0\end{array}$ & $\begin{array}{c}\text { Droplet } \\
\text { diameter } \\
\mathrm{d} / \mathrm{mm}\end{array}$ & $\begin{array}{c}\text { Drops } \\
\text { height } \\
\mathrm{h} / \mathrm{mm}\end{array}$ & $\begin{array}{c}\text { Wetting } \\
\text { angle } \theta / \%\end{array}$ \\
\hline 2.02 & 0.34 & 37.5 & 1.90 & 0.84 & 82.9 \\
\hline
\end{tabular}

\section{2 Hardener Robustness Test Results}

The bond strength of soft rock grassroots with the film of cured is important to evaluate the quality indicators of the curing agent and it largely determines the curing agent application possibilities and reliability. The method is called scarification that scratch tool using the surface coating layer in the sample under test depicts certain regular shape fixed pattern (as shown in Figure 2. 2 (a) below), according to the case between the scratch off layer (Figure 2.2 (b) below) to determine the bond strength and rock surface hardener. Figure 2.2 and Table 2.3 shows the effect of cement content on the curing agent in combination with soft rock surface strength. After the samples of soft rock were cured, Si-OH in the curing agent and $-\mathrm{OH}$ in the sample of soft rock surface dehydration condensation reaction to form a strong bond Si-O-Si bond, and a curing agent to form a rock surface integral, continuous closed structure, with excellent fastness.

Table 2. 2 Curing agents and rock surface bonding strength results

\begin{tabular}{|c|c|c|}
\hline Number & Number shedding & Percentage loss \\
\hline 1 & 3 & $3 \%$ \\
\hline
\end{tabular}

\section{3 Curing Agents Waterproof Test Results Analysis}

Changes in absorption contrast rock samples soaking process to determine the curing agent waterproof rock samples before and after curing agent curing. Soft rock absorption refers to the rock sample completely immersed in water, after a certain period of time, the ratio of the weight of water in rock samples sucked to drying rock samples weight. The tests in accordance with the provisions of the specific steps GB MT42-80 were measured, but also to be ready to observe and record the time and phenomenon of the soft rock cracks and disintegration in water during the test. For the rock sample has disintegrated, should be used filter paper to absorb moisture, and then measure the weight of the soft rock samples absorbent.

As can be seen from Figure 2.3, carbonaceous shale sample is immersed in water before curing, the water molecules quickly penetrate soft rock inside the larger pores, the water absorption increased rapidly, larger pores after the lapse of time gradually being filled with water absorption growth is slowing down; After curing, due to the curing agent polymer and soft rock surface hydroxyl groups interact to form interwoven mesh film. Between the polymer molecules will have a width of a gap of about a few nanometers, under normal circumstances, a single water molecule can 
through these gaps. Since the nature of the water normally associated state exists, due to the hydrogen bonding of water molecules to form a larger water molecules, in this case, water molecules in reality difficult to pass between the solid polymer clearance. So waterproof coating prevents moisture penetration by water molecules, polymers can effectively slow down rate of the water molecules inside the pore penetration of soft rock, water absorption, slow growth, seven days of water absorption by the unmodified $1.9 \%$ dropped to 0.42 percent.

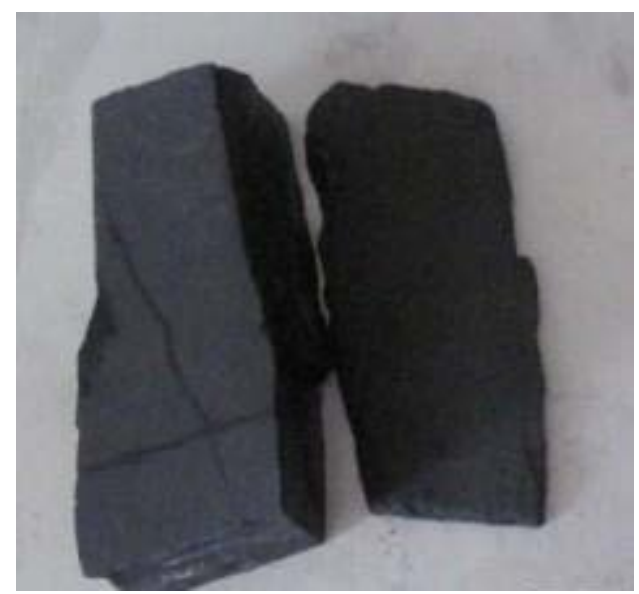

(a) Before curing

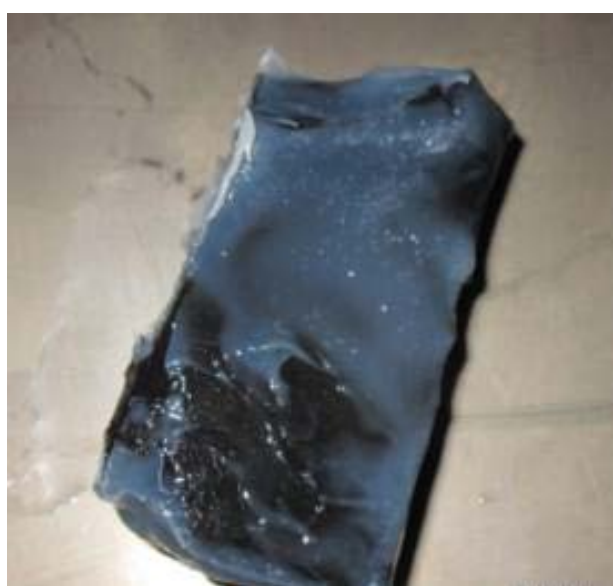

(b) cured

Figure 2. 2 the rock sample soaked failure modes

Table 2. 3 Measured values of different soaking time for soft rock mass changes

\begin{tabular}{|c|c|c|c|c|c|c|c|c|}
\hline $\begin{array}{c}\text { Soaked } \\
\text { time/day }\end{array}$ & 0 & 1 & 2 & 3 & 4 & 5 & 6 & 7 \\
\hline $\begin{array}{c}\text { Before } \\
\text { curing }\end{array}$ & 279.32 & 284.52 & 284.59 & 284.6 & 284.62 & 284.63 & 284.65 & 284.67 \\
\hline cured & 257.48 & 257.5 & 257.54 & 257.59 & 257.73 & 257.96 & 258.23 & 258.57 \\
\hline
\end{tabular}

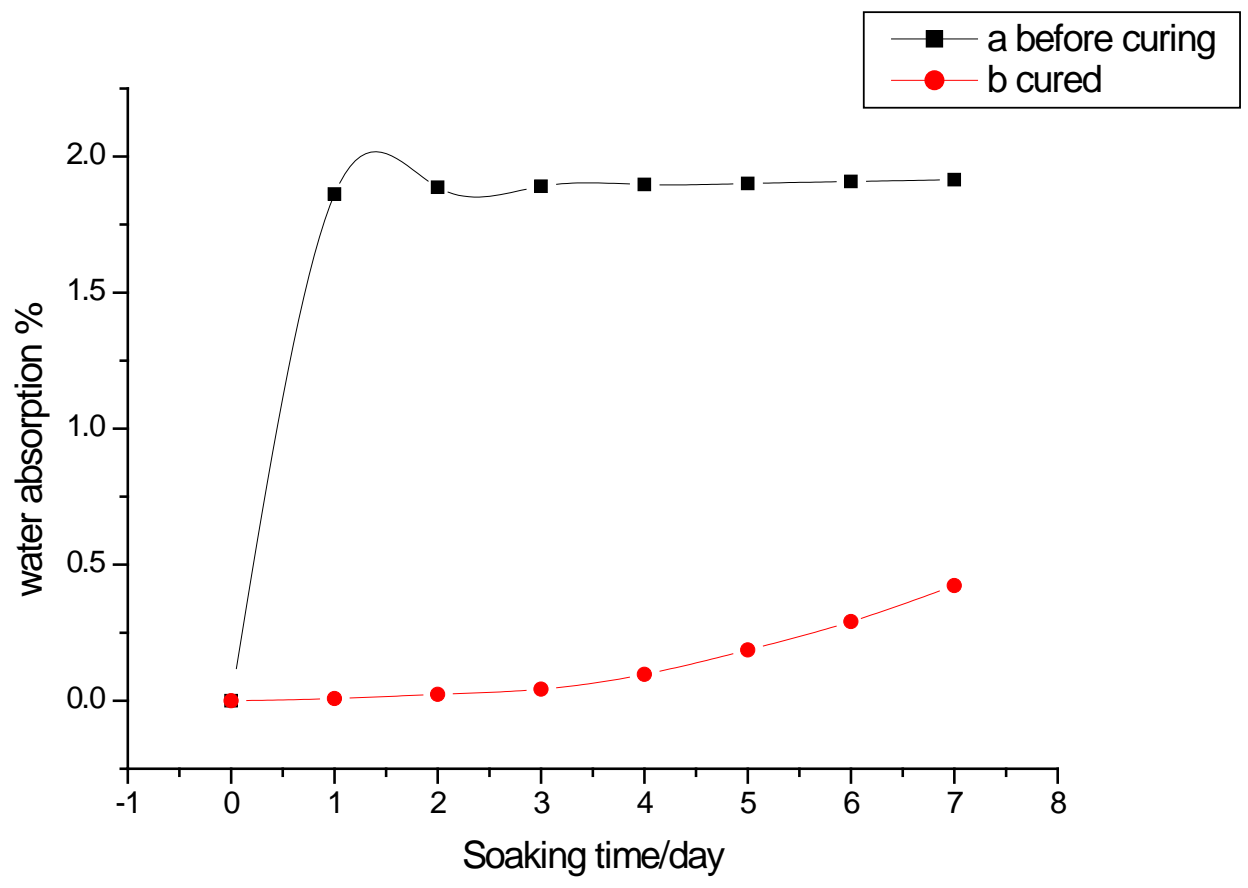

Figure 2. 3a Soft Rock absorption and immersion time curve 


\section{4 The Impact of Curing Agents after Soaking the Rock Sample Microstructure Analysis}

New polymer cement composite curing agents for soft rock solidified rock samples before and after immersion microscopic structural changes in Figure 2.4. Soft rock samples before curing flooding microstructure is shown in Figure 2.4(a), soft rocks rough surface of the particles, and the rugged, large pores. After curing, the soft rock soaking microstructure between particles combine more closely, surface roughness, porosity less in Figure 2.4(b).

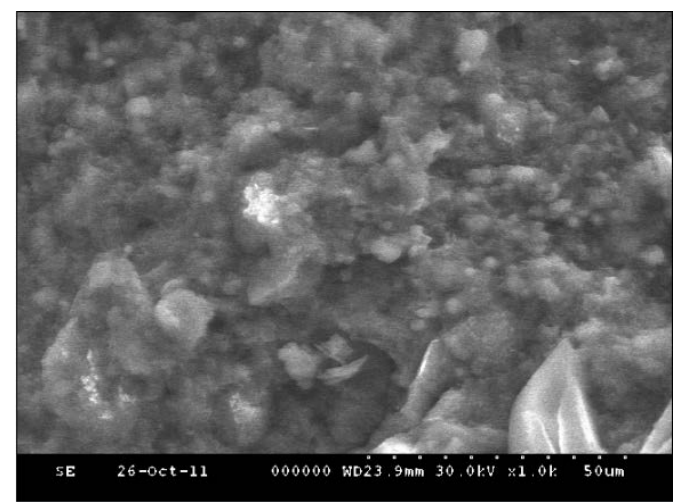

(a) Before curing

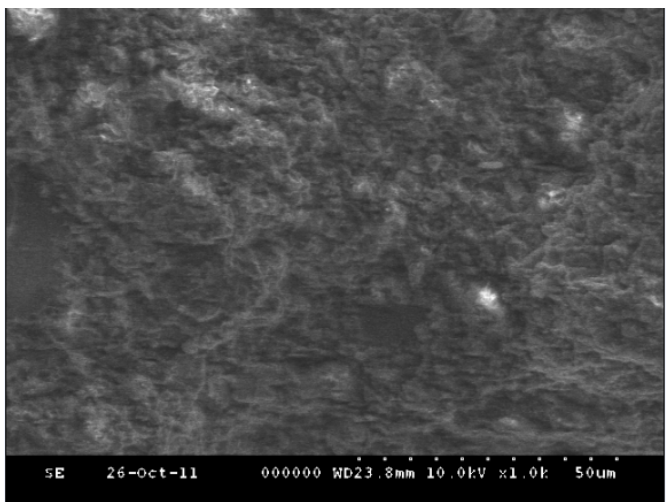

(b) cured

Figure 2. 4b Soft Rock samples before and after curing flooding microstructure

To further investigate the influence of curing agents after soft rock microstructure water to establish a dynamic relationship between curing agents types and micro indicators between soft rock must study the microstructure changes during deformation. curing agents treated for soft rock SEM image processing can be reflected in a number of structural parameters of soft rock microstructure and its changes. These structural parameters reflect different aspects of soft rock unit body size and shape and pore structure characteristics of the deformation process, the arrangement characteristics and corresponding variation. Depending on the object, and the problem of this study, the choice of pore size as a quantitative parameter microstructure research. Using matlab software, soft rock sample SEM image processing, obtained by post-curing agent pore area per unit area has decreased from 6.54 to 3.71, the pore size was significantly reduced, only 56.7 percent before curing. After the polymer cement material which is applied to the soft rock, since the polymer infiltration, can penetrate the polymer cement penetration into microscopic pores, thus reducing the pore space.

\section{Curing Mechanism Analysis}

Polymer modified cement waterproofing materials have characteristics of both volatile and curing. Polymer emulsion with the cement hydration and water evaporates can form a film having a high bond strength at the surface of the cement hydration products, and some polymer filled with cement hydration products porosity middle, so hardened cement becomes more dense. Polymer film forming and cement hydration is at the same time accelerate the curing speed emulsion, cement polymer film and the final product after hydration intertwined to form a network of interconnected structural layers. Also some of the polymer emulsion polymer organic groups are active, have a chemical reaction capability, the product may be associated with the solid surface of the cement hydration or calcium hydroxide silicate chemical reaction, which may increase the hydration of cement from the microscopic structure connection between the bonding capacity of the product, thereby improving the adhesion of ordinary grout itself after hydration properties. Grid structure film to maintain the inorganic silicate cement material aging can be a compression strength, high hardness characteristics, but also has the organic polymer material good flexibility, excellent structural closure and easy brushing characteristics. 


\section{Conclusions}

1) Through scarification, static water contact angle method, soft rock sample absorption and SEM microscopic analysis and other physical and chemical testing methods for polymer cement composite curing agents acrylic resin polymer materials were prepared by physical analyze chemical properties. The film of firmness, hydrophobicity and water resistance were investigated and measured, the surface wetting angle by the unmodified 37.5 degrees up to 82.9 degrees after modification, water absorption rate of 7 days decreased from $1.9 \%$ unmodified to modified $0.42 \%$.

2) By processing the soft rock SEM graphics, the soft rock after curing the pore area unit area decreased from 6.54 to 3.71 , the pore size was decreased. The polymer cement curing effect is good.

\section{Acknowledgement}

This research was financially supported by the National Natural Science Foundation(51378082).

\section{References}

[1] Cui Zhengquan, Li Ning. Slope engineering recent advances in theory and practice[M]. beijing: China Water Power Press, 1999

[2] Wang Ge Development and application of polymer cement composites[D]:[Changsha University of Science \& Technology master's degree thesis]. Changsha: Changsha University of Science \& Technology, 2012

[3]Jie Chaohua,Zhu Bingguang. Polymer-cement-based composite waterproof coating application technology[J]. china building waterproofing. 1996. (2):22- 24

[4] Zhang Zhiqiang, Dong song. The impact of each component polymer cement-based composite waterproof coating on its performance[J].Water-proof Materials and Construction. 2002. (11):21- 25

[5] Che Ping, Huang Hongwei, Xue yadong, Zhang richen. Mechanical properties of roadway floor Mudstone cured body[J] . journal of building materials. 2007. 10(6):658-664

[6]ChaiZhaoyun, Kang Tianhe. Evaluation of silicon modified resin coated soft rock with high montmorillonite content and its effects[J]. Chinese Journal of Rock Mechanics and Engineering. 2009. 28(1):82-86

[7]Huang He, Shi Bin. Water-physical properties of expansive soils modified by STW ecotypic soil stabilizer[J]. Chinese Journal of Geotechnical Engineering. 2008. (2):8- 11 